\title{
Early infection with Leishmania major restrains pathogenic response to Leishmania amazonensis and parasite growth
}

\author{
C.Z. González-Lombana ${ }^{\text {a }}$, H.C. Santiago ${ }^{\text {a }}$, J.P. Macedo ${ }^{\text {a }}$, V.A.R. Seixas ${ }^{\text {a }}$, \\ R.C. Russo ${ }^{\mathrm{a}}$, W.L. Tafuri ${ }^{\mathrm{b}}$, L.C.C. Afonso ${ }^{\mathrm{c}}$, L.Q. Vieira ${ }^{\mathrm{a}, *}$ \\ a Departamento de Bioquímica e Imunologia, Instituto de Ciências Biológicas (ICB), Universidade Federal de Minas Gerais, \\ CP 486, 31270-901 Belo Horizonte, MG, Brazil \\ ${ }^{\mathrm{b}}$ Departamento de Patologia Geral, Instituto de Ciências Biológicas (ICB), Universidade Federal de Minas Gerais, \\ CP 486, 31270-901 Belo Horizonte, MG, Brazil \\ ${ }^{\mathrm{c}}$ Departamento de Ciências Biológicas, Instituto de Ciências Exatas e Biológicas and Núcleo de Pesquisa em Ciências Biológicas, \\ Universidade Federal de Ouro Preto, Morro do Cruzeiro, 35400-000 Ouro Preto, MG, Brazil
}

Received 2 October 2007; received in revised form 26 November 2007; accepted 21 December 2007

Available online 15 January 2008

\begin{abstract}
Experimental models of infection with Leishmania spp. have provided knowledge of several immunological events involved in the resistance mechanism used by the host to restrain parasite growth. It is well accepted that concomitant immunity exists, and there is some evidence that it would play a major role in long-lasting acquired resistance to infection. In this paper, the resistance to Leishmania amazonensis infection in C57BL/6 mice infected with Leishmania major was investigated. C57BL/6 mice, which spontaneously heal lesions caused by infection with $L$. major, were infected with $L$. amazonensis at different times before and after L. major. We demonstrated that C57BL/6 mice previously infected with L. major restrain pathogenic responses induced by L. amazonensis infection and decrease parasite burdens by one order of magnitude. Coinfected mice showed production of IFN- $\gamma$ in lesions similar to mice infected solely with $L$. major, but higher TNF- $\alpha$ and nitric oxide synthase (iNOS) mRNA expression was observed. Surprisingly, the restrained pathogenic response was not related to IL-10 production, as evidenced by lower levels of both mRNA, protein expression in lesions from co-infected mice and in co-infections in IL-10 ${ }^{-/-}$mice. Examination of the inflammatory infiltrate at the site of infection showed a reduced number of monocytes and lymphocytes in L. amazonensis lesions. Additionally, differential production of the CCL3/MIP-1 $\alpha$ and CCL5/RANTES was observed. We suggest that the control of lesion progression caused by $L$. amazonensis in C57BL/6 mice pre-infected with L. major is related to the induction of a down-regulatory environment at the site of infection with L. amazonensis.
\end{abstract}

(C) 2008 Elsevier B.V. All rights reserved.

Keywords: Protozoan parasites; Cutaneous leishmaniasis; Co-infection; Cellular recruitment

\section{Introduction}

Several experimental models have been used to determine the susceptibility and resistance mechanisms triggered by infection with Leishmania parasites. Leishmania major infection has been considered as a unique model of host resistance and susceptibility to Leishmania. Most mouse strains are considered resistant to

\footnotetext{
* Corresponding author at: Departamento de Bioquímica e Imunologia, ICB, Universidade Federal de Minas Gerais, CP 486, 30161-970 Belo Horizonte, MG, Brazil. Tel.: +55 313409 2656; fax: +55 3134092614 .

E-mail address: lqvieira@icb.ufmg.br (L.Q. Vieira).
}

L. major infection but a few strains, such as BALB/C and CBA/J develop a progressive, nonhealing disease. However, L. major resistant mice are susceptible to infection with Leishmania amazonensis (Afonso and Scott, 1993; Lemos de Souza et al., 2000).

It is postulated that in protective immunity, usually acquired during the latent and chronic phase following cutaneous infection with Leishmania, CD4+ T cells, IL-12, IFN- $\gamma$ and inducible nitric oxide synthase (iNOS) maintain the immune pressure against parasite growth (Afonso and Scott, 1993; Soong et al., 1996; Jones et al., 1998; Mukbel et al., 2007). Impairment of these responses during latency has been shown to promote parasite growth, pathology and the reappearance of lesions (Stenger et al., 1996; Mendez et al., 2004). In fact, susceptibility 
to L. amazonensis infection has been described not only as associated with defective IFN- $\gamma$ production (Afonso and Scott, 1993) but also with specific impairment of the cell-mediated immune response at the early stages of infection (Ji et al., 2003) and deficient production of TNF- $\alpha$ by macrophages (Gomes et al., 2003). So, unlike infection with L. major, there is a delayed expression of multiple inflammatory mediators during $L$. amazonensis infection, which are correlated with reduced T-cell responsiveness.

Several experimental strategies trigger protection against infection with Leishmania, such as vaccination and crossimmunity (Alexander and Phillips, 1978, 1980; Coelho et al., 2003; Vanloubbeeck and Jones, 2004; Uzonna et al., 2004; Ji et al., 2005; Dondji et al., 2005; Hernandez et al., 2006). Antigen persistence appears to be a critical factor for the maintenance of protective immunity (Belkaid et al., 2001; Uzonna et al., 2001), and this has been the basis for the use of live parasites to immunize humans (Khamesipour et al., 2005) Some experimental studies have shown relative protection against $L$. amazonensis infection after vaccination with live parasites (Veras et al., 1999; Vanloubbeeck and Jones, 2004). In one report, previous infection with L. major rendered $\mathrm{C} 3 \mathrm{H}$ mice more resistant to L. amazonensis than naïve controls (Veras et al., 1999; Vanloubbeeck and Jones, 2004). However, it was not clear from these studies what were the mechanisms involved in this resistance. In the present work, we attempt to more fully define the degree of protection generated by the use of previous infection with L. major and the immunological mechanisms involved in this protection.

\section{Materials and methods}

\subsection{Mice and parasites}

Female C57BL/6 mice were purchased from CEBIO (Instituto de Ciências Biológicas, UFMG Belo Horizonte, MG, Brazil). Mice deficient in IL-10 (IL-10 ${ }^{-1-}$ ) by homologue recombination in the $\mathrm{C} 57 \mathrm{BL} / 6$ background (originally from Jackson Laboratories, B6.129P2-IllO ${ }^{t m l C g n}$ ) were bred at the Gnotobiology facility (Instituto de Ciências Biologicas). All mice were 8-week old at the time of infection. $L$. major (WHO MHOM/IL/80/Friedlin) and L. amazonensis (IFLA/BR/67/PH8) promastigotes were grown to the stationary phase in Grace's insect cell culture medium (GIBCO BRL, Grand Island, NY, USA) supplemented with $20 \%$ heat-inactivated fetal bovine serum (FBS, Cultilab, Campinas, SP, Brazil), $2 \mathrm{mM}$ L-glutamine, $100 \mathrm{U}$ of penicillin and $100 \mu \mathrm{g}$ of streptomycin $/ \mathrm{mL}$. Infective stage metacyclic promastigotes of parasites were isolated from stationary culture (5-6 days old) (Spath and Beverley, 2001) and washed twice in phosphate-buffered saline $\mathrm{pH} 7.3$ (PBS) before they were used for infection. Freeze-thawed leishmanial antigen was obtained from stationary-phase promastigotes that were washed twice in PBS, resuspended in PBS and subjected to seven freeze-thaw cycles consisting of -70 and $37^{\circ} \mathrm{C}$. The protein concentration was determined by the Lowry assay (Lowry et al., 1951) the final concentration was adjusted to $1 \mathrm{mg} / \mathrm{mL}$, and aliquots were stored at $-70{ }^{\circ} \mathrm{C}$ before use.

\subsection{Infections}

Mice were inoculated subcutaneously with $1 \times 10^{4}$ stationary-phase L. major or L. amazonensis promastigotes into one hind footpad. Simultaneously or at different time points after infection, mice were infected subcutaneously with $1 \times 10^{4}$ parasites of the other Leishmania species in $40 \mu \mathrm{lde}$ PBS in the contralateral footpad. Lesion size was monitored weekly with dial micrometer and the results were expressed as the difference in thickness between infected footpads and non-infected footpads of control mice. The parasite burden was determined by performing a limiting dilution analysis as previously described (Vieira et al., 1996). In brief, the homogenates of infected lesions were serially diluted (1:10 or 1:4 serial dilutions) in Grace's insect culture medium plus $20 \%$ FBS and observed 5-7 days later for growth of promastigotes. Parasite numbers are expressed as the negative $\log _{10}$ dilution at which promastigote growth was observed. Results are expressed as mean $\log _{10}$ of the inverse of the titer.

\subsection{Histopathological analysis}

L. amazonensis-infected footpads were collected at 10 weeks post L. amazonensis infection, fixed in $10 \%$ phosphate-buffered formalin and embedded in paraffin. Tissues were sectioned at $5 \mu \mathrm{M}$ thickness, mounted onto slides and stained with hematoxylin and eosin. Histological examinations were performed under a light microscope in an Olympus microscopy using 100-400-fold magnification.

\subsection{Cytokine production by lymph nodes and spleens}

Spleen and draining lymph node cells from infected mice were harvested and made into single cell suspensions. In brief, the cells were washed, resuspended at $5 \times 10^{6} / \mathrm{mL}$ of complete RPMI 1640 medium (Gibco Laboratories) supplemented with $10 \%$ heat-inactivated FBS, $25 \mathrm{mM}$ HEPES, $0.05 \mathrm{mM} 2-$ mercaptoethanol, $2 \mathrm{mM}$ L-glutamine, $100 \mathrm{U} / \mathrm{mL}$ penicillin and $100 \mu \mathrm{g} / \mathrm{mL}$ streptomycin, and plated at $1 \mathrm{~mL}$ per well in 24well tissue culture plates (Costar, New York, NY, USA.). Cells were re-stimulated in the presence of $50 \mu \mathrm{g} / \mathrm{mL}$ Leishmania antigen freeze-thawed lysates of promastigotes of L. amazonensis or L. major, respectively. Culture supernatants were collected after $72 \mathrm{~h}$ and analyzed for their IFN- $\gamma$ and IL-4 content by capture enzyme-linked immunosorbent assay (ELISA) (sensitivity 80-150 pg/mL). IL-10 production was measured using ELISA kit (R\&D systems, Minneapolis, MN, USA), as indicated by the manufacturer (sensitivity $31.25 \mathrm{pg} / \mathrm{mL}$ ).

\subsection{Measurement of chemokines and cytokines in footpads by ELISA}

Concentration of the chemokines CCL2 (MCP-1), CCL3 (MIP-1 $\alpha$ ), CCL5 (RANTES) and CXCL10 (IP-10) and the cytokines IL-10 and TGF- $\beta 1$ in L. amazonensis-infected footpads was measured at different times post L. amazonensis infection. Foot tissues were homogenized in PBS $(0.4 \mathrm{M} \mathrm{NaCl}$ 
and $10 \mathrm{mM}$ de $\mathrm{Na}_{2} \mathrm{HPO}_{4}, \mathrm{pH}$ 7.2) containing anti-proteases (0.1 mM phenylmethylsulfonyl fluoride, $0.1 \mathrm{mM}$ benzethonium chloride, $10 \mathrm{mM}$ EDTA and $20 \mathrm{mM}$ KI aprotinin A/100 mL) and $0.05 \%$ Tween-20. Homogenized tissues were kept on ice for $30 \mathrm{~min}$ and subsequently centrifuged $(3000 \times \mathrm{g}$ for $10 \mathrm{~min})$. Supernatants recovered were diluted in PBS (1:4) and tested for each chemokine or cytokine using commercially available antibodies and according to the procedures supplied by the manufacturer (R\&D Systems). All samples were assayed in duplicates. The threshold of sensitivity for each cytokine or chemokine was $7.5 \mathrm{pg} / \mathrm{mL}$.

\subsection{Detection of $m R N A$ by reverse transcription and real-time reverse-transcribed polymerase chain reaction $(P C R)$ in footpad}

At different time points after $L$. amazonensis infection, total RNA was isolated from L. amazonensis-infected footpads for real-time polymerase chain reaction (RT-PCR) as previously described (Cummings and Tarleton, 2004). Briefly, RNA was isolated from footpads using Trizol (Invitrogen, Carlsbad, CA, USA) followed by a phenol-chloroform-isoamyl alcohol affinity extraction. Purity of RNA was confirmed by a ratio of readings at $260 / 280 \mathrm{~nm}$. $1 \mu \mathrm{g}$ of RNA was reversetranscribed into cDNA. The amplification of specific mRNA expression was achieved by RT-PCR using specific primer sequences for specific primer sequences for IFN- $\gamma$, TNF- $\alpha$, iNOS, and IL-10 (Giulietti et al., 2001). The reactions were performed on an ABI PRISM 7900HT sequence detection system (Applied Biosystems) using 20\% of the cDNA reaction in a total volume of $20 \mu \mathrm{L}$ of PCR mixture. All PCR reactions were performed in duplicate using a SYBR Green PCR Master Mix according to the manufacturer's recommendations. The relative quantification of products was determined by the comparative threshold cycle method to determine fold increases in product. Each gene of interest was normalized to the hypoxanthine phosphoribosyl transferase (HPRT forward, GTTGGATACAGGCCAGACTTTGTT; HPRT reverse, GATTCAACTTGCGCTCATCTTAGGC), based on $\Delta \triangle \mathrm{CT}$ calculation. The fold change in expression was represented as relative to naïve controls. Five footpads were used per group for each time point.

\subsection{Statistical procedures}

Results are expressed as mean \pm S.D. To determine whether differences were statistically significant, the Student's $t$-test was performed using a two-tailed distribution with unpaired samples. Differences were considered to be statistically significant if $p<0.05$.

\section{Results}

\subsection{Lesion progression due to L. amazonensis is controlled by C57BL/6 mice previously infected with L. major}

To evaluate the effect of pre-infection with $L$. major on the course of infection with L. amazonensis, C57BL/6 mice were injected with $1 \times 10^{4}$ stationary-phase L. major promastigotes and challenged with L. amazonensis in the contralateral or the same footpad at different time points. As seen in Fig. 1, lesion sizes following L. amazonensis infection were significantly reduced when mice were infected with L. major for 3 (A) or 15 (B) weeks. L. amazonensis loads were reduced by previous infection with L. major (Fig. $1 \mathrm{E}$ and F), L. amazonensis numbers were smaller at 6 and 10 weeks after L. amazonensis infection in mice pre-infected with L. major for 15 weeks, when lesions were already different. Interestingly, in mice challenged 3 weeks after the first infection, L. amazonensis loads did not differ at 6 weeks after challenge, but at 10 weeks a reduction in parasitism of about 25 times was found, when compared to animals infected solely with L. amazonensis $\left(1.4 \log _{10}\right.$, Fig. 1E, $p<0.05)$. Noteworthy, at this time point, lesions were very different in size between the two groups, and mice previously infected with L. major had almost completely healed their L. amazonensis lesions. To exclude the possibility that the smaller lesions in mice previously infected with $L$. major mice were due to a switch from a cutaneous form into a visceral form of infection, we determined the parasite load in spleens and draining lymph nodes. Parasite burdens in draining lymph nodes were comparable in both groups $\left(1.6 \log _{10} \pm 0.7\right.$ and $\left.2.4 \log _{10} \pm 0.5\right)$. Moreover, no parasites were recovered from spleens from either group of mice. Simultaneous infections in the same footpad or in different footpads did not interfere in the lesion sizes or parasite burdens, when compared with mice solely infected with $L$. amazonensis (Fig. 1C, D, G and H). In addition, lesions caused by $L$. major were not affected by the subsequent or simultaneous infection with L. amazonensis, as shown in Fig. 2A-D. These results indicate that C57BL/6 mice pre-infected with $L$. major were able to control lesion progression by L. amazonensis and reduce, albeit not completely control, parasite burdens.

\subsection{Control of lesion progression of L. amazonensis infection by mice previously infected with L. major is associated with reduced inflammatory infiltrate}

In order to investigate the basis of the protection induced by L. major, sections from footpad tissues were examined. An extensive inflammatory infiltrate was apparent in lesions from mice infected solely with $L$. amazonensis, 10 weeks after infection (Fig. 3A). These lesions contained a dense infiltrate of inflammatory cells, which were characterized by diffuse areas of cellular infiltration with lymphocytes, macrophages, polymorphonuclear leukocytes and occasional plasma cells. Vacuolated macrophages were present which contained one or several amastigotes (Fig. 3A, arrow). In contrast, reduced cellular infiltration was observed in lesions from mice pre-infected with $L$. major at the same time point (Fig. 3B). Although parasitized cells were apparent in L. amazonensis lesions from pre-infected or naïve mice, in lesions from pre-infected mice most infected macrophages were preferentially accumulated in limited areas of deep dermis (Fig. 3B, arrow). It should be mentioned that, although the inflammation and total infected area were significantly smaller in mice pre-infected with $L$. major, the parasite 

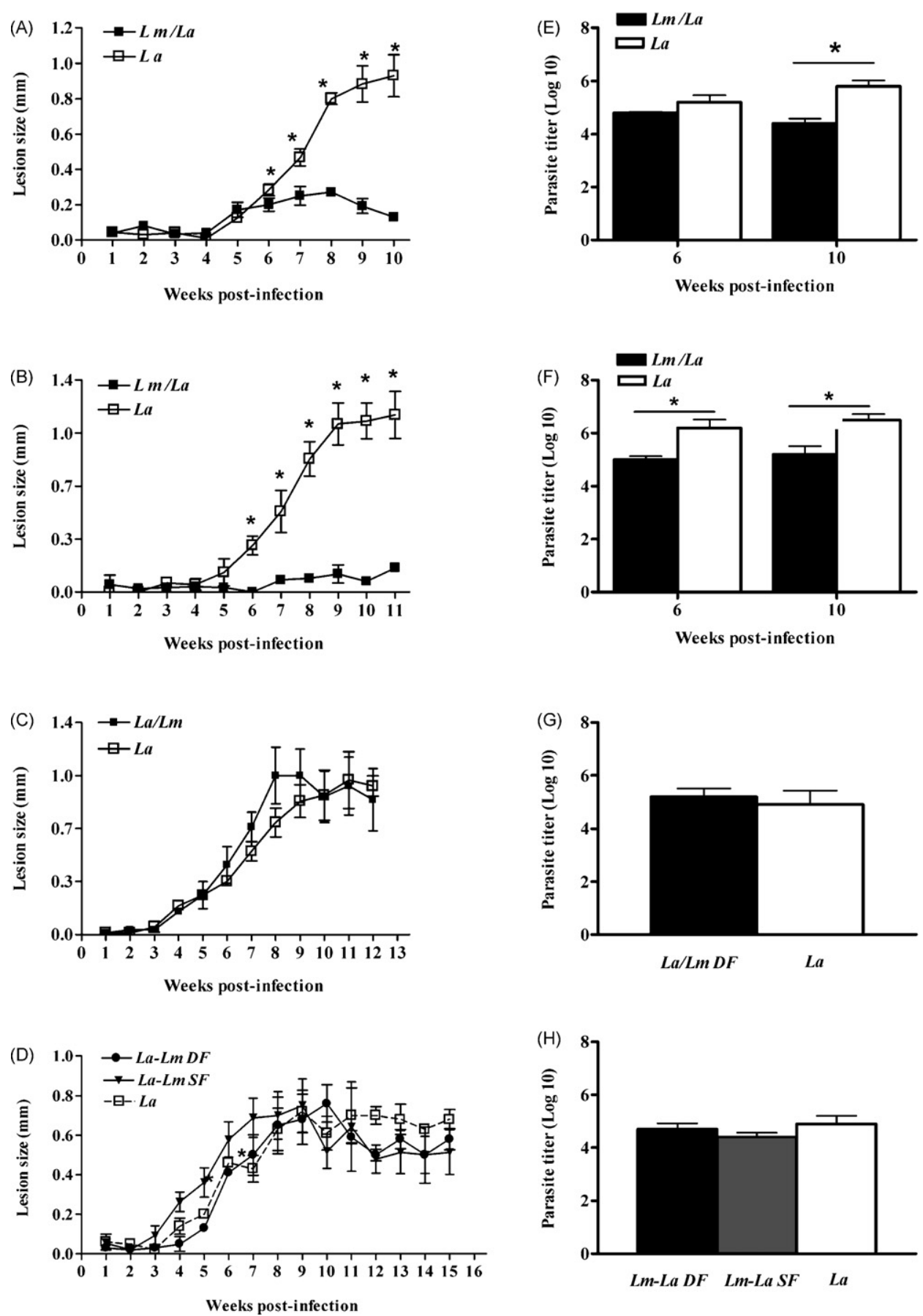

Fig. 1. C57BL/6 mice pre-infected with $L$. major control progression of L. amazonensis lesions. C57BL/6 mice infected with $1 \times 10^{4}$ stationary-phase $L$. major or $L$. amazonensis were infected simultaneously or challenged at different time points after infection with the other Leishmania species. Lesion sizes of the $L$. amazonensis-infected footpads were monitored over time and expressed as the difference between the footpad thickness of the infected foot and the footpad thickness of the uninfected foot, taken prior to challenge. The values are the mean \pm S.D. of lesion sizes. (A and B) C57BL/6 mice were infected in the right hind footpad with $1 \times 10^{4}$ stationary-phase L. major promastigotes. Three (A) or fifteen (B) weeks after infection, mice were challenged in the contralateral footpad with $1 \times 10^{4}$ stationary-phase L. amazonensis promastigotes (labeled $\mathrm{Lm} / \mathrm{La}$ ). (C) C57BL/6 mice were infected in the right hind footpad with $1 \times 10^{4}$ stationary-phase $L$. amazonensis promastigotes and challenged in the contralateral footpad with $1 \times 10^{4}$ stationary-phase $L$. major promastigotes 3 weeks later ( La/Lm). (D) C57BL/6 mice were infected simultaneously in the same footpad $(L a-L m S F)$ or in different footpad $(L a-L m D F)$ with $1 \times 10^{4}$ stationary-phase $L$. major and $L$. amazonensis promastigotes. Control groups consisted of mice infected only with $L$. amazonensis promastigotes $(\mathrm{La})$. (E, F, G, and $\mathrm{H})$ Estimated number of parasites in the infected footpads at 6 and $10(\mathrm{E}$ and F), $12(\mathrm{G})$ and $15(\mathrm{H})$ weeks post-infection, by limiting dilution analysis. Parasite numbers on the right column correspond to the course of infection in the left column. *A statistically significant difference $(p<0.05$, by Student's $t$-test). The results were representative of one experiment of three separate experiments performed with five mice per group. 

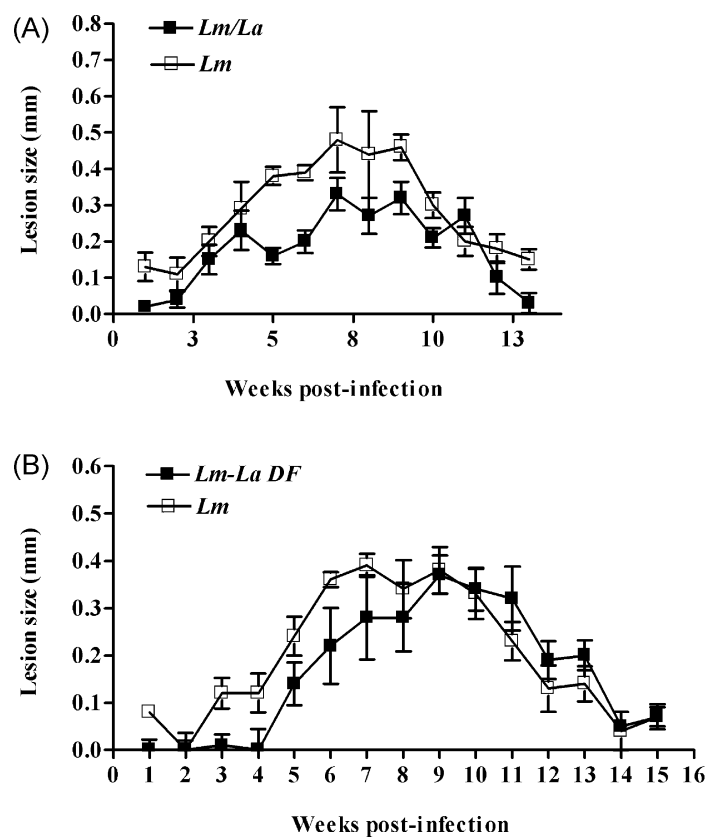
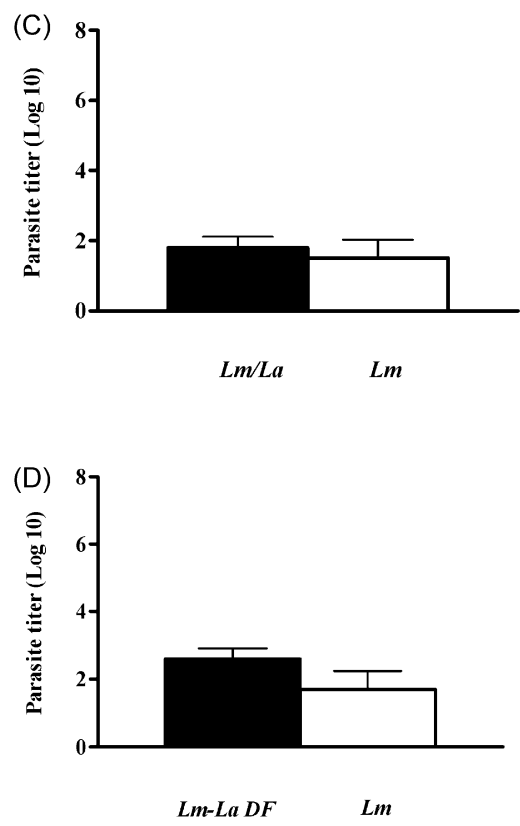

Fig. 2. Concomitant infection with L. major and L. amazonensis does not alter $L$. major infection. C57BL/6 mice infected previously with $1 \times 10^{4}$ stationary-phase $L$. major promastigotes were infected simultaneously or challenged later with $L$. amazonensis. (A) Lesion sizes in the $L$. major-infected footpad in C57BL/6 mice infected with $L$. major and challenged with $L$. amazonensis 3 weeks later $(L m / L a)$ or $(B)$ infected simultaneously with $L$. major and $L$. amazonensis promastigotes in different footpads $(L a-L m D F)$. Control groups consisted of mice infected only with $L$. major $(L m)$. Lesion size was monitored over time with a dial micrometer and was expressed as the difference between the footpad thickness of the infected foot and the footpad thickness of the uninfected foot, taken prior to challenge. The values are the mean \pm S.D. of lesion sizes. (C) Estimated number of parasites in the L. major-infected footpads at 13 weeks post-infection by limiting dilution analysis. (D) Estimated number of parasites in the L. major-infected footpads at 15 weeks post-infection by limiting dilution analysis. *A statistically significant difference ( $p<0.05$, by Student's $t$-test). The results were representative of one experiment of three separate experiments performed with five mice per group.
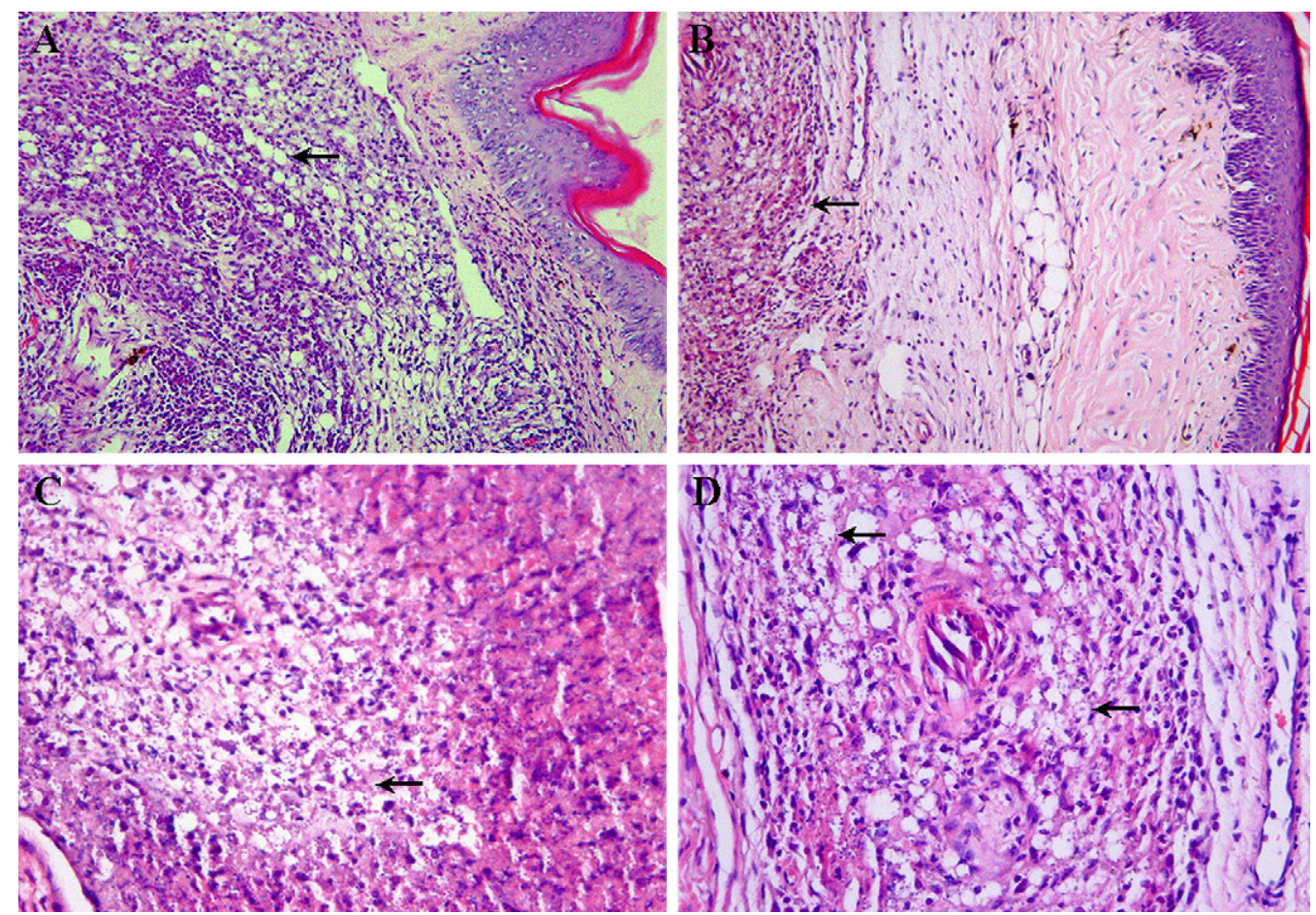

Fig. 3. Histological aspects of lesions from mice pre-infected with L. major and challenged with L. amazonensis. C57BL/6 mice were infected in the right hind footpad with $1 \times 10^{4}$ stationary-phase $L$. major promastigotes. Three weeks later mice were infected in the contralateral footpad with $1 \times 10^{4}$ stationary-phase $L$. amazonensis promastigotes, and sacrificed 10 weeks after infection with L. amazonensis. Tissue sections from lesions were recovered and evaluated. (A) Lesion from a control mouse infected only with $L$. amazonensis showing larger inflammatory infiltrate than (B) lesions from mice pre-infected with $L$. major. Numerous vacuolated and parasitized macrophages were preferentially accumulated in limited areas (arrows in A and B). C and D show parasites in lesions from mice infected with L. amazonensis (C) or pre-infected with L. major (D), at a higher magnification. The arrows indicate parasites inside macrophages. The tissue sections were processed for hematoxylin and eosin staining as described in Section 2. A and B magnification $200 \times, \mathrm{C}$ and D magnification $400 \times$. 
density in selected foci within the lesion tissue appeared high (Fig. 3C and D, arrows) and thus parasite burdens were coherent with the quantification by limiting dilution.

\subsection{IL-10 has no effect on control of lesion progression of \\ L. amazonensis induced by previous infection with L. major}

IL-10 has been implicated in the control of lesion sizes and to promote persistence of parasites during $L$. major infections (Belkaid et al., 2001). To determine whether IL-10 plays a role on the regulation of lesions or persistence of parasites in mice previously infected with $L$. major and challenged with L. amazonensis, we compared infection outcome in C57BL/6 mice genetically deficient in the gene for IL-10 (IL-10 ${ }^{-/-}$) and wild-type mice. L. amazonensis-infected $\mathrm{IL}-10^{-1-}$ and C57BL/6 mice developed similar lesion evolution (Fig. 4A). When IL-10 ${ }^{-/-}$mice were pre-infected with $L$. major and subsequently with $L$. amazonensis, they controlled lesions caused
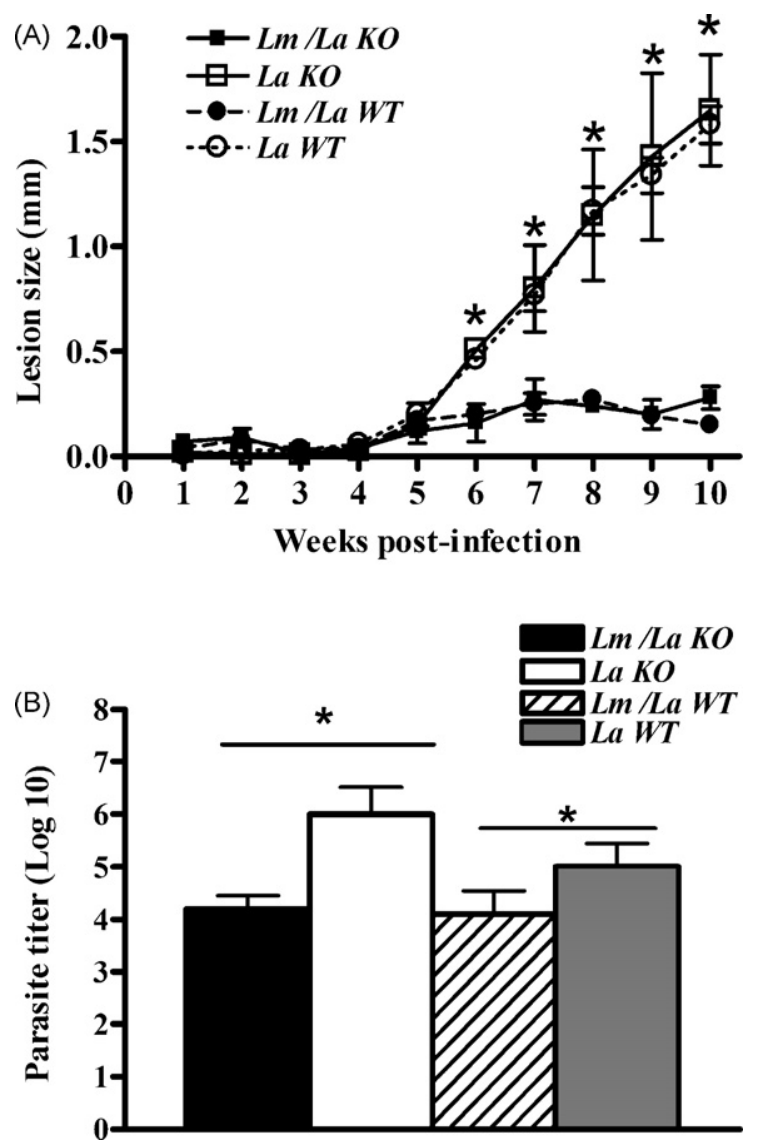

Fig. 4. Course of mixed infection with L. amazonensis and L. major in IL-10-1mice. (A) Mean lesion size produced by $1 \times 10^{4} \mathrm{~L}$. amazonensis stationary promastigotes in IL-10 ${ }^{-/-}$mice infected previously $(\mathrm{Lm} / \mathrm{La} \mathrm{KO}$ ) or not $(\mathrm{La} \mathrm{KO})$ in the contralateral footpad with $10^{4} \mathrm{~L}$. major stationary promastigotes. The courses of infection of C57BL/6 mice infected previously ( $L m / L a W T)$ or not $\left(\right.$ LaWT) in the contralateral footpad with $10^{4}$ L. major are also shown. Results are presented as mean \pm S.D. between infected and uninfected footpads. (B) Parasite burden from $L$. amazonensis lesions at 10 weeks after infection. *A statistically significant difference ( $p<0.05$, by Student's $t$-test). The results presented are of one experiment representative of two performed independently, with five mice per group. by L. amazonensis similarly to WT animals. Importantly, both IL-10 ${ }^{-1-}$ and C57BL/6 mice infected with L. amazonensis alone developed persistent lesions and high tissue parasitism. Preinfected IL- $10^{-/-}$mice not only developed smaller lesions, similarly to C57BL/6 WT mice, but also displayed a reduction of almost $2 \log$ on footpad parasite loads, when compared to non-pre-infected IL-10 $10^{-/-}$controls. Pre-infected WT mice had a reduction of approximately $1 \log$, when compared to non-preinfected WT.

\subsection{IFN- $\gamma$ production by mice previously infected with $L$. major is higher than in mice solely infected with $L$. amazonensis}

Since susceptibility and pathogenesis to cutaneous leishmaniasis may be associated with the relative levels of IFN- $\gamma$ and IL-4 production in mice, we assessed these cytokines. IL$10^{-1-}$ and C57BL/6 mice pre-infected with $L$. major and later infected with L. amazonensis were sacrificed 6 or 10 weeks after L. amazonensis infection and cells from spleens and lymph nodes draining L. amazonensis lesions were cultured in vitro for $72 \mathrm{~h}$ following stimulation with freeze-thawed promastigotes as described in Section 2 (Fig. 5). The analysis of IFN- $\gamma$ production by spleen cells at 6 and 10 weeks post-infection demonstrated that cells from C57BL/6 mice previously infected with L. major (stimulated either with L. major antigen or L. amazonensis antigen) produced higher amounts IFN- $\gamma$ than C57BL/6 mice infected solely with L. amazonensis (Fig. 5A and B). IFN- $\gamma$ production by spleen cells stimulated with L. amazonensis antigen was smaller than that of cells stimulated with L. major antigen. IFN- $\gamma$ production by draining lymph nodes from both groups of WT mice was comparable at 6 and 10 weeks (Fig. 5D and E). In IL-10 $10^{-1}$ mice previously infected with $L$. major, the detected IFN- $\gamma$ levels by both spleen and draining lymph node cells were higher when compared to animals infected only with L. amazonensis (Fig. 5C and F). IL-4 production was not detected by ELISA. In previous work, we have tried to detect IL-4 extensively by ELISA, ELISPOT and antibody isotype in sera from C57BL/6 mice infected with L. amazonensis and have failed (Hernandez et al., 2006). Our current data is in accordance with our previous data. These data indicate that the pre-infection with $L$. major increases IFN- $\gamma$ production by spleen cells, but IFN- $\gamma$ response is not affected in draining node lymph of the $L$. amazonensis lesions.

\section{5. iNOS, inflammatory cytokines and chemokines in lesions by L. amazonensis in pre-infected mice}

Several studies addressed the early response to Leishmania infection and have shown that both cytokines and chemokines are important to this response (Ritter et al., 1996; Arnoldi and Moll, 1998; Ritter and Moll, 2000; Bhattacharyya et al., 2002; Santiago et al., 2004; Vasquez and Soong, 2006). To test the hypothesis that the reduced cellular infiltrate in the L. amazonensis lesions from pre-infected mice was related directly with alterations in inflammatory chemokines and cytokines in situ, we extended our analysis to measure mRNA transcripts and pro- 

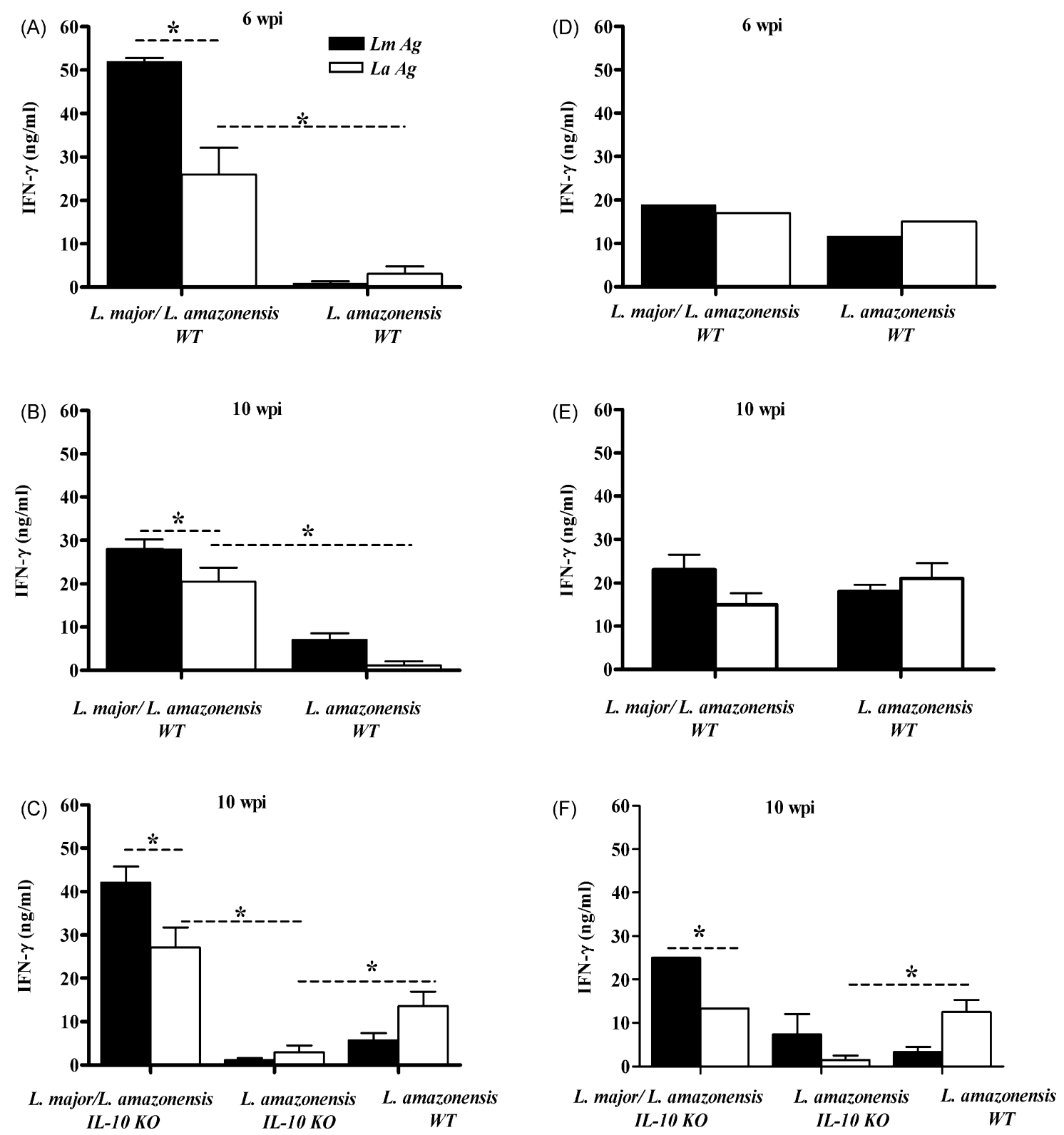

Fig. 5. IFN- $\gamma$ production by spleen cells from mice pre-infected with $L$. major and challenged with $L$. amazonensis is higher than $L$. amazonensis-infected mice. Spleen (A, B and C) and lymph node cells (D, E and F) cells from C57BL/6 (WT) and IL-10 ${ }^{-/-}(I L-10 \mathrm{KO})$ mice pre-infected with $L$. major and challenged with $L$. amazonensis 3 weeks later were stimulated in vitro in the presence of $L$. major $(L m \mathrm{Ag})$ or $L$. amazonensis $(\mathrm{La} \mathrm{Ag})$ antigen and culture supernatants were harvested $72 \mathrm{~h}$ later and assayed for IFN- $\gamma$. Results in (C) are from pooled lymph nodes. IFN- $\gamma$ was measured by ELISA at 6 and 10 weeks post $L$. amazonensis-infection (wpi). The values are the mean \pm S.D. *A statistically significant difference $(p<0.05$, by Student's $t$-test). One of three experiments (five mice per experiment) is shown.

tein expression levels in foot tissues at different points after $L$. amazonensis infection. Total mRNAs were isolated from footpad tissues and cytokines gene expression was examined by real-time PCR. Coherently with draining lymph node data, the expression of IFN- $\gamma$ in the lesion did not differ between preinfected or not pre-infected animals (Fig. 6A). On the other hand, the expression of iNOS and TNF were found up-regulated in L. major-previously infected animals when compared to controls infected only with L. amazonensis (Fig. 6B and C). iNOS transcripts were also higher in the pre-infected mice at 10 weeks post-infection (Fig. 6B). Another striking difference was observed in the IL-10 expression: IL-10 transcripts in lesions from pre-infected mice were approximately 15- and 142-fold lower than the levels in L. amazonensis lesions from mice without previous infection at 3 and 10 weeks post-infection with L. amazonensis, respectively. Interestingly, expression of IL-10 mRNA was barely detectable at 6 weeks post-infection with L. amazonensis (Fig. 6D). Levels of IL-10 protein were also consistently lower in extracts from L. amazonensis lesions of pre-infected mice than in $L$. amazonensis lesions from mice infected just with L. amazonensis (Fig. 7A).

Chemokines have been implicated on different outcomes of infection and in control or parasite replication (Ritter et al., 1996; Aliberti et al., 1999; Ritter and Korner, 2002; Santiago et al., 2004; Vasquez and Soong, 2006). Thus, we investigated whether the levels of lesion chemokines in L. amazonensis 

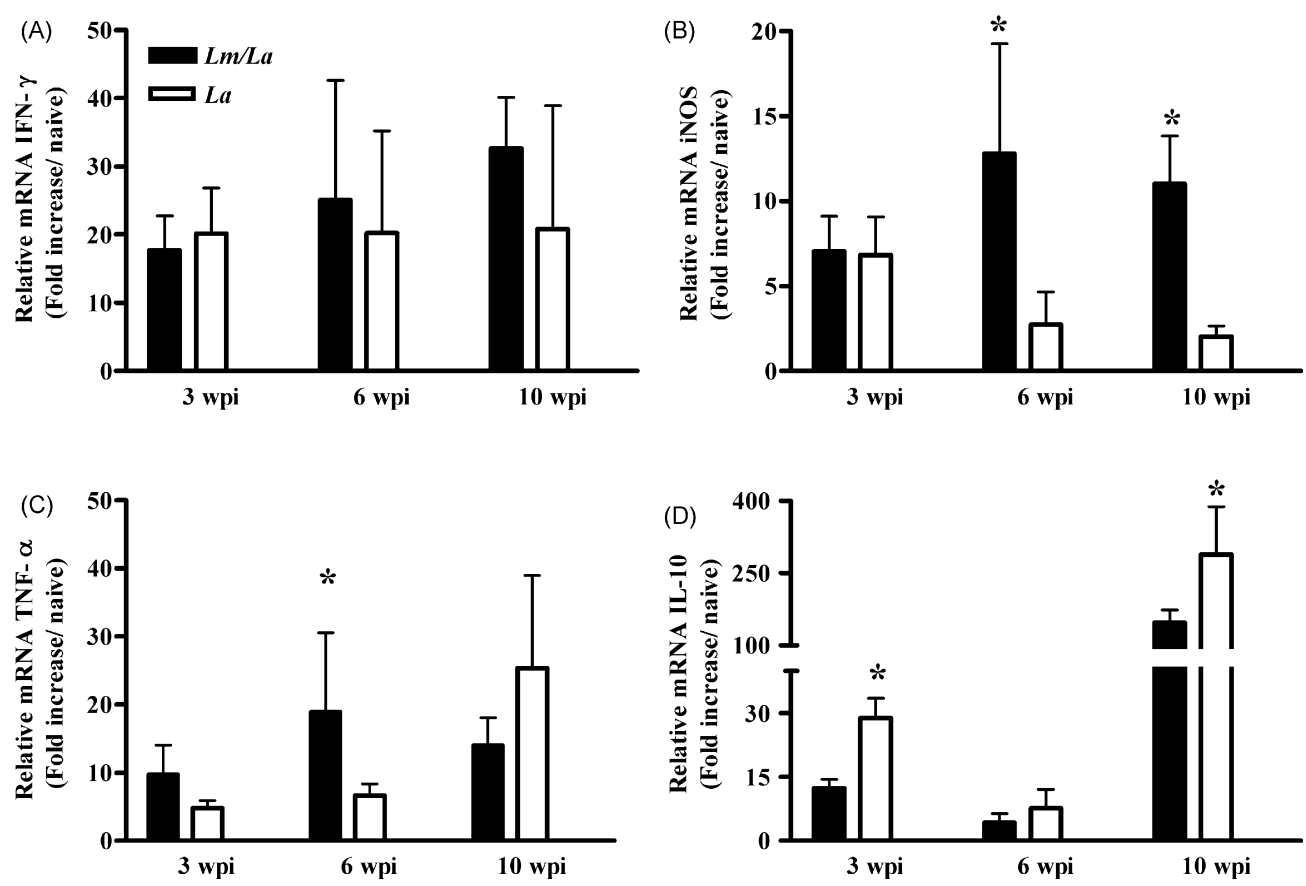

Fig. 6. IFN- $\gamma$ (A), iNOS (B), TNF- $\alpha$ (C) and IL-10 (D) message levels in lesions from mice pre-infected with $L$. major and challenged with $L$. amazonensis. C57BL/6 mice were pre-infected with $L$. major and challenged with L. amazonensis 3 weeks later. The hind L. amazonensis-infected footpad was assayed for mRNA expression. Total RNA was isolated directly from the L. amazonensis-infected footpad at the indicated times during the infection, reverse-transcribed, and analyzed by real-time RT-PCR. The target genes were normalized to the endogenous control, and the values shown are the fold increase relative to expression in naïve footpad. Each bar is the mean \pm S.D. of five individual footpads from mice from pre-infected mice with $L$. major $(L m / L a)$ or solely infected with $L$. amazonensis (La). *A statistically significant difference ( $p<0.05$, by Student's $t$-test). One of three experiments (five mice per experiment) is shown.

lesions from mice pre-infected with L. major was different from lesions from mice infected just with L. amazonensis. Chemokine levels were assessed in homogenates of footpads infected with L. amazonensis by ELISA (Fig. 7). Infection with L. amazonensis up-regulated CCL2/MCP-1 when compared to naïve mice at both 6 and 10 weeks after infection (Fig. 7B) in a manner not influenced by pre-infection with L. major. On the other hand, no significant up-regulation of CXCL10/IP-10 was found (Fig. 7C). In contrast, different levels were observed for CCL5/RANTES and CCL3/MIP- $1 \alpha$ between experimental groups (Fig. 7D and E). While at 6 weeks of infection with $L$. amazonensis CCL5/RANTES protein was significantly higher in lesions from L. major pre-infected mice, at 10 weeks lesions from pre-infected mice showed less CCL5/RANTES than lesions from mice infected only with $L$. amazonensis (Fig. 7D). At 6 weeks of infection, CCL3/MIP-1 $1 \alpha$ levels in $L$.
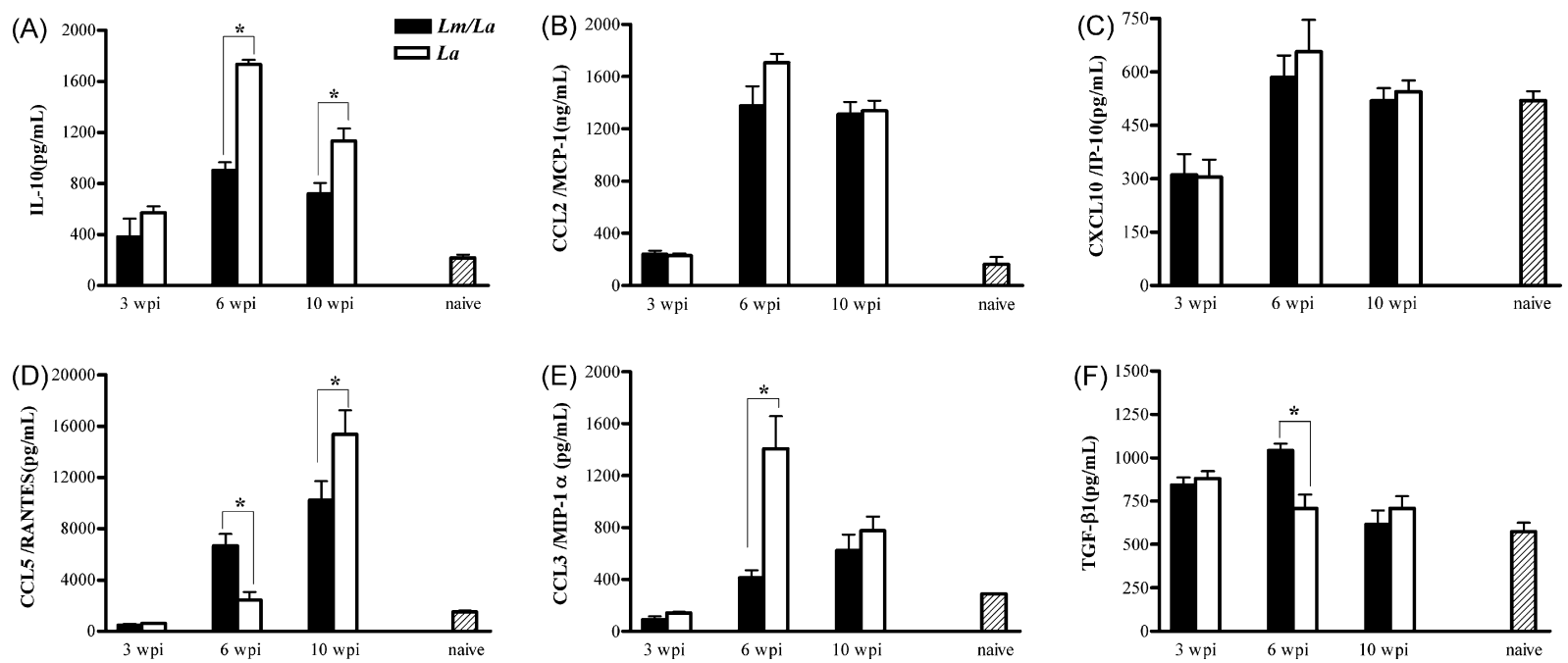

Fig. 7. Chemokine and cytokine levels in lesions from mice pre-infected with $L$. major and challenged with L. amazonensis. Foot tissue homogenates were prepared from $L$. amazonensis lesions at different times post-infection with $L$. amazonensis, as described in Section 2. The levels of IL-10 (A), CCL2/MCP-1 (B), CXCL10/IP10 (C), CCL5/RANTES (D), CCL3/MIP-1 $\alpha$ (E) and TGF- $\beta 1$ were determined by ELISA. The results are shown as means \pm S.D. for six mice, in two independent experiments containing three mice each. *A statistically significant difference $(p<0.05$, by Student's $t$-test). 
amazonensis lesions from pre-infected mice were smaller at than those from their counterparts infected just with L. amazonensis (Fig. 7E). Low levels of CCL5/RANTES and CCL3/MIP- $1 \alpha$ were observed at 3 weeks post-infection with L. amazonensis (Fig. 7D and E).

Although several reports have demonstrated that IL-10 contributes to the suppression of the immunity to Leishmania infection (Fiorentino et al., 1991; Rocha et al., 1999; Belkaid et al., 2001; Kane and Mosser, 2001; Buxbaum and Scott, 2005; Anderson et al., 2007), TGF- $\beta 1$ also plays a role in suppression of the immune response (Barral-Netto et al., 1992). Thus, we also assessed the levels of TGF- $\beta 1$ (as protein in lesions) during of development of lesions. An analysis during infection revealed an early increase in TGF- $\beta 1$ after infection with L. amazonensis, although no differences were observed in the TGF- $\beta 1$ levels among groups at 3 and 10 weeks post-infection and naïve mice. In contrast, there were differences between the two groups at 6 weeks post-infection, when pre-infected mice showed a higher level of TGF- $\beta 1$ than mice without previously infection (Fig. 7F).

\section{Discussion}

Several studies have demonstrated that the host response to leishmaniasis is determined by the species or strain of Leishmania (Barral et al., 1983; Calabrese and da Costa, 1992; Afonso and Scott, 1993; Soong et al., 1996; Anderson et al., 2005). In fact, L. amazonensis infections in most L. major resistant mouse strains result in the development of chronic lesions containing persistent parasite loads (Afonso and Scott, 1993; Soong et al., 1996; Jones et al., 2000; Ramer et al., 2006). Nevertheless, several papers have demonstrated cross-immunity between Leishmania species either using Leishmania antigens or live promastigotes and, although some Leishmania species may confer protection against others (Alexander and Phillips, 1978; Alexander, 1982; Alexander and Kaye, 1985; De Rossell et al., 1987; Coelho et al., 2003; Vanloubbeeck and Jones, 2004; Mukbel et al., 2006), at present, the mechanism responsible for this cross-protection is not yet known. In this work we studied co-infections with L. amazonensis and L. major in C57BL/6 mice.

A dramatic alteration in the course of infection by L. amazonensis was observed in mice that had been previously inoculated with L. major. Hence, lesions were smaller in these mice, regardless of the time of the previous challenge with L. amazonensis. This process may be related in part with enhanced parasite killing, as evidenced by a reduction in parasite burdens in $L$. amazonensis lesions from C57BL/6 mice pre-infected with $L$. major, both by parasite quantification and histological analysis. This reduction in parasite burden is in sharp contrast with the one reported by Vanloubbeeck and Jones (2004), who showed a difference of four orders of magnitude between groups similar to ours. In that study, the authors used $\mathrm{C} 3 \mathrm{Heb} / \mathrm{FeJ}$ mice. $\mathrm{C} 3 \mathrm{H} / \mathrm{HeN}$ and $\mathrm{C} 3 \mathrm{H} / \mathrm{HeJ}$ mice have been shown to have higher $\mathrm{NK}$ activity than C57BL/6 mice, and also higher IFN- $\gamma$ and lower IL-4 production in response to infection with $L$. major (Scharton and $\mathrm{Scott}, 1993)$. If the same is true for $\mathrm{C} 3 \mathrm{Heb} / \mathrm{FeJ}$ mice, a higher NK cell response may explain the larger differences in parasite burdens found by Vanloubbeeck and Jones (2004). The reduction we found in the parasite burden in L. amazonensis lesions cannot be attributed to dissemination of the parasite to other tissues (Barral et al., 1986; Ramos-Santos et al., 2000; Vanloubbeeck et al., 2005) since, at 10 weeks of infection, the number of parasites recovered from of draining lymph nodes in pre-infected infected mice was not higher than those in mice not pre-infected with L. major. Protection conferred by L. major was dependent on the time of infection. Hence, lesions due to L. amazonensis, as well as parasite numbers, were not altered if $L$. major was given simultaneously or after infection with L. amazonensis. These data were indicative of a role of priming of the immune system with $L$. major prior to infection with L. amazonensis in order to obtain the protective effect observed.

We observed higher production of IFN- $\gamma$ by spleen cells from L. major pre-infected mice in weeks 6 and 10 after infection with $L$. amazonensis. However, IFN- $\gamma$ production by draining lymph node cells and IFN- $\gamma$ mRNA in lesions were not different between pre-infected mice and their controls. Hence, although pre-infection with L. major contributes to the increase of systemic antigen-specific production of IFN- $\gamma$, the response to $L$. amazonensis at the site of infection did not seem to dramatically affect the production of IFN- $\gamma$. However, higher levels of transcripts for TNF- $\alpha$ and iNOS were found in pre-infected mice, as well as lower levels of IL-10. Therefore, the smaller numbers of parasites found could be explained by a higher local level of iNOS, induced by activation by IFN- $\gamma$ (which is similar in both groups) and TNF- $\alpha$ (which is higher in the pre-infected group) (Green et al., 1990). Consequently, the synergism of these two cytokines could have caused enhanced killing in the pre-infected group. It has been shown that addition of TNF- $\alpha$ to macrophages infected with L. amazonensis overcomes the defective killing of these parasites in vitro (Gomes et al., 2003). The lower levels of IL-10 may also have favored the higher expression of iNOS (Gazzinelli et al., 1992; Kane and Mosser, 2001; Jones et al., 2002).

Impaired microbicidal activity would not, clearly, be solely dependent of the expression of IL-10 as described for L. major (Anderson et al., 2005), since the parasites persist even in absence of this cytokine (IL-10 ${ }^{-/-}$mice), as shown here. Clearly, IL-10 ${ }^{-1-}$ mice use other mechanisms to control lesions and parasite burdens, one of them being the up-regulation of IFN- $\gamma$ shown here.

Control of parasites was not complete in pre-infected mice. In this setting, we asked how pre-infected mice controlled progressive L. amazonensis lesions without markedly reducing the number of parasites. Examination of the inflammatory infiltrate at the site of parasite inoculation revealed reduced recruitment of monocytes and lymphocytes into L. amazonensis lesions. Also, histological analysis showed that in lesions from pre-infected mice, most infected macrophages accumulated in limited areas of deep dermis. Hence, lesion progression in pre-infected mice is markedly associated with an alteration of cell recruitment.

Several inflammatory and chemoattractant cytokines are involved in the immunoregulatory process and cell migration in leishmaniasis. For instance, the absence of IL-10 has shown to 
be related with lesion and parasite burden reduction in BALB/c mice infected with L. amazonensis (Kane and Mosser, 2001). In IL-10 $-1-$ in the C57BL/6 background, however, lower parasite burdens and higher Th1 response than the wild type were found, even though lesion sizes were similar between the two groups (Jones et al., 2002). Our data do not argue for a role of IL-10 in the control of lesions sizes in co-infected mice, since lesion progression was similar in IL- $10^{-/-}$mice pre-infected with L. major if compared to wild-type controls, as well as in mice infected solely with $L$. amazonensis. In addition, IL-10 levels were smaller in L. major pre-infected wild-type mice when compared with levels found in wild-type mice solely infected with L. amazonensis, again speaking against a role for IL-10 in controlling lesion sizes. These results are consistent with other data previously published (Jones et al., 2002).

Increased expression of chemokines is the earliest response of macrophages to L. major infection (Racoosin and Beverley, 1997; Ji et al., 2003; Dasgupta et al., 2003). In humans, CCL2/MCP-1 was associated with healing of disease (Ritter et al., 1996), however, we found that CCL2/MCP-1, as well as CXCL10/IP-10 levels were similar in both groups; in fact CXCL10/IP-10 was not up-regulated in the footpads in response to infection. These results are consistent with the fact that similar levels of IFN- $\gamma$ were found in footpads from both groups, since CCL2/MCP-1 and CXCL10/IP-10 are induced by IFN- $\gamma$ (Ritter and Moll, 2000; Muzio et al., 2000; Zaph and Scott, 2003; Steigerwald and Moll, 2005). The sustained and high production of CCL2/MCP-1 after 3 weeks might be responsible for the maintenance of macrophages in lesions in both groups (Ritter et al., 1996; Ritter and Moll, 2000). In contrast to CCL2/MCP1 and CXCL10/IP-10, we observed differential production of the other $\beta$-chemokines (CCL3/MIP- $1 \alpha$ and CCL5/RANTES). CCL3/MIP-1 $\alpha$ levels were lower in pre-infected mice at 6 weeks post-infection than in mice infected just with $L$. amazonensis. This chemokine is associated with granulomatous condition (Lukacs et al., 1993) and some authors suggest that this chemokine is responsible for the increased cellularity of granulomatous lesions (Hogaboam et al., 1997). Thus, it is possible that the increased cellularity in mice infected only with L. amazonensis might be the outcome of the increased CCL3/MIP- $1 \alpha$ levels. CCL5/RANTES was slightly increased in pre-infected mice at 6 weeks of infection, but was dramatically increased at 10 weeks in mice infected just with L. amazonensis. At 10 weeks of infection lesions were significantly larger in L. amazonensis-infected mice than in pre-infected mice. The delayed and reduced expression of CCL5/RANTES described in mice infected with L. amazonensis (Ji et al., 2003) is likely overcome by pre-infection with $L$ major. It is tempting to speculate that reduced CCL3 and CCL5 expression in pre-infected mice could be related with the clustered distribution of the infected macrophages in lesions at 10 weeks of infection.

In summary, the findings presented here indicate that preinfection with $L$. major can significantly modify the lesion progression caused by L. amazonensis without complete parasite control. The concomitant infection with $L$. major and $L$. amazonensis results in the induction of a down-regulatory environment in the site of infection with L. amazonensis, site which seems to be related with differential chemokines expression and altered composition of the cellular infiltrate.

\section{Acknowledgements}

This work was supported by CAPES, FAPEMIG grant CBB87 and by CNPq grant 350567/1995-6. RCR is a CAPES fellow, all other authors are $\mathrm{CNPq}$ fellows. We are indebted to Mr. Antonio Mesquita Vaz for expert animal care.

\section{References}

Afonso, L.C.C., Scott, P., 1993. Immune responses associated with susceptibility of C57BL/10 mice to Leishmania amazonensis. Infect. Immun. 61, 2952-2959.

Alexander, J., 1982. A radioattenuated Leishmania major vaccine markedly increases the resistance of CBA mice to subsequent infection with Leishmania mexicana mexicana. Trans. R. Soc. Trop. Med. Hyg. 76, 646-649.

Alexander, J., Kaye, P.M., 1985. Immunoregulatory pathways in murine leishmaniasis: different regulatory control during Leishmania mexicana mexicana and Leishmania major infections. Clin. Exp. Immunol. 61, 674-682.

Alexander, J., Phillips, R.S., 1978. Leishmania tropica and Leishmania mexicana: cross-immunity in mice. Exp. Parasitol. 45, 93-100.

Alexander, J., Phillips, R.S., 1980. Leishmania mexicana and Leishmania tropica major: adoptive transfer of immunity in mice. Exp. Parasitol. 49, 34-40.

Aliberti, J.C., Machado, F.S., Souto, J.T., Campanelli, A.P., Teixeira, M.M., Gazzinelli, R.T., Silva, J.S., 1999. beta-Chemokines enhance parasite uptake and promote nitric oxide-dependent microbiostatic activity in murine inflammatory macrophages infected with Trypanosoma cruzi. Infect. Immun. 67, 4819-4826.

Anderson, C.F., Mendez, S., Sacks, D.L., 2005. Nonhealing infection despite Th1 polarization produced by a strain of Leishmania major in C57BL/6 mice. J. Immunol. 174, 2934-2941.

Anderson, C.F., Oukka, M., Kuchroo, V.J., Sacks, D., 2007. CD4(+)CD25(-)Foxp3(-) Th1 cells are the source of IL-10-mediated immune suppression in chronic cutaneous leishmaniasis. J. Exp. Med. 204, 285-297.

Arnoldi, J., Moll, H., 1998. Langerhans cell migration in murine cutaneous leishmaniasis: regulation by tumor necrosis factor alpha, interleukin-1 beta, and macrophage inflammatory protein-1 alpha. Dev. Immunol. 6, 3-11.

Barral, A., Badaro, R., Barral-Netto, M., Grimaldi Jr., G., Momem, H., Carvalho, E.M., 1986. Isolation of Leishmania mexicana amazonensis from the bone marrow in a case of American visceral leishmaniasis. Am. J. Trop. Med. Hyg. 35, 732-734.

Barral, A., Petersen, E.A., Sacks, D.L., Neva, F.A., 1983. Late metastatic leishmaniasis in the mouse. A model for mucocutaneous disease. Am. J. Trop. Med. Hyg. 32, 277-285.

Barral-Netto, M., Barral, A., Brownell, C.E., Skeiky, Y.A., Ellingsworth, L.R., Twardzik, D.R., Reed, S.G., 1992. Transforming growth factor-beta in leishmanial infection: a parasite escape mechanism. Science 257, 545-548.

Belkaid, Y., Hoffmann, K.F., Mendez, S., Kamhawi, S., Udey, M.C., Wynn, T.A., Sacks, D.L., 2001. The role of interleukin (IL)-10 in the persistence of Leishmania major in the skin after healing and the therapeutic potential of anti-IL-10 receptor antibody for sterile cure. J. Exp. Med. 194, 1497-1506.

Bhattacharyya, S., Ghosh, S., Dasgupta, B., Mazumder, D., Roy, S., Majumdar, S., 2002. Chemokine-induced leishmanicidal activity in murine macrophages via the generation of nitric oxide. J. Infect. Dis. 185 1704-1708.

Buxbaum, L.U., Scott, P., 2005. Interleukin 10- and Fcgamma receptor-deficient mice resolve Leishmania mexicana lesions. Infect. Immun. 73, 2101-2108.

Calabrese, K.S., da Costa, S.C., 1992. Enhancement of Leishmania amazonensis infection in BCG non-responder mice by BCG-antigen specific vaccine. Mem. Inst. Oswaldo Cruz 87 (Suppl. 1), 49-56.

Coelho, E.A., Tavares, C.A., Carvalho, F.A., Chaves, K.F., Teixeira, K.N., Rodrigues, R.C., Charest, H., Matlashewski, G., Gazzinelli, R.T., Fernandes, 
A.P., 2003. Immune responses induced by the Leishmania (Leishmania) donovani $\mathrm{A} 2$ antigen, but not by the LACK antigen, are protective against experimental Leishmania (Leishmania) amazonensis infection. Infect. Immun. 71, 3988-3994.

Cummings, K.L., Tarleton, R.L., 2004. Inducible nitric oxide synthase is not essential for control of Trypanosoma cruzi infection in mice. Infect. Immun. 72, 4081-4089.

Dasgupta, B., Roychoudhury, K., Ganguly, S., Akbar, M.A., Das, P., Roy, S., 2003. Infection of human mononuclear phagocytes and macrophage-like THP1 cells with Leishmania donovani results in modulation of expression of a subset of chemokines and a chemokine receptor. Scand. J. Immunol. 57, 366-374.

De Rossell, R.A., Bray, R.S., Alexander, J., 1987. The correlation between delayed hypersensitivity, lymphocyte activation and protective immunity in experimental murine leishmaniasis. Parasite Immunol. 9, 105-115.

Dondji, B., Perez-Jimenez, E., Goldsmith-Pestana, K., Esteban, M., MahonPratt, D., 2005. Heterologous prime-boost vaccination with the LACK antigen protects against murine visceral leishmaniasis. Infect. Immun. 73, 5286-5289.

Fiorentino, D.F., Slotnik, A., Mosmann, T.R., Howard, M., O’Garra, A., 1991. IL-10 inhibits cytokine production by activated macrophages. J. Immunol. $147,3815-3822$

Gazzinelli, R.T., Oswald, I.P., James, S.L., Sher, A., 1992. IL-10 inhibits parasite killing and nitrogen oxide production by IFN-gamma-activated macrophages. J. Immunol. 148, 1792-1796.

Giulietti, A., Overbergh, L., Valckx, D., Decallonne, B., Bouillon, R., Mathieu, C., 2001. An overview of real-time quantitative PCR: applications to quantify cytokine gene expression. Methods 25, 386-401.

Gomes, I.N., Calabrich, A.F., Tavares, R.S., Wietzerbin, J., De Freitas, L.A., Veras, P.S., 2003. Differential properties of CBA/J mononuclear phagocytes recovered from an inflammatory site and probed with two different species of Leishmania. Microbes Infect. 5, 251-260.

Green, S.J., Crawford, R.M., Hockmeyer, J.T., Meltzer, M.S., Nacy, C.A., 1990 Leishmania major amastigotes initiate the L-arginine-dependent killing mechanism in IFN-gamma-stimulated macrophages by induction of tumor necrosis factor-alpha. J. Immunol. 145, 4290-4297.

Hernandez, M.X., Barcante, T.A., Vilela, L., Tafuri, W.L., Afonso, L.C., Vieira, L.Q., 2006. Vaccine-induced protection against Leishmania amazonensis is obtained in the absence of IL-12/23p40. Immunol. Lett. 105, 38-47.

Hogaboam, C.M., Chensue, S.W., Steinhauser, M.L., Huffnagle, G.B., Lukacs, N.W., Strieter, R.M., Kunkel, S.L., 1997. Alteration of the cytokine phenotype in an experimental lung granuloma model by inhibiting nitric oxide. J. Immunol. 159, 5585-5593.

Ji, J., Masterson, J., Sun, J., Soong, L., 2005. CD4+CD25+ regulatory T cells restrain pathogenic responses during Leishmania amazonensis infection. J. Immunol. 174, 7147-7153.

Ji, J., Sun, J., Soong, L., 2003. Impaired expression of inflammatory cytokines and chemokines at early stages of infection with Leishmania amazonensis. Infect. Immun. 71, 4278-4288.

Jones, D., Elloso, M.M., Showe, L., Williams, D., Trinchieri, G., Scott, P., 1998. Differential regulation of the interleukin-12 receptor during the innate immune response to Leishmania major. Infect. Immun. 66, 38183824.

Jones, D.E., Ackermann, M.R., Wille, U., Hunter, C.A., Scott, P., 2002. Early enhanced Th1 response after Leishmania amazonensis infection of C57BL/6 interleukin-10-deficient mice does not lead to resolution of infection. Infect. Immun. 70, 2151-2158

Jones, D.E., Buxbaum, L.U., Scott, P., 2000. IL-4-independent inhibition of IL12 responsiveness during Leishmania amazonensis infection. J. Immunol. $165,364-372$

Kane, M.M., Mosser, D.M., 2001. The role of IL-10 in promoting disease progression in leishmaniasis. J. Immunol. 166, 1141-1147.

Khamesipour, A., Dowlati, Y., Asilian, A., Hashemi-Fesharki, R., Javadi, A., Noazin, S., Modabber, F., 2005. Leishmanization: use of an old method for evaluation of candidate vaccines against leishmaniasis. Vaccine 23 3642-3648.

Lemos de Souza, V., Ascencao Souza, J., Correia Silva, T.M., Sampaio Tavares Veras, P., Rodrigues de-Freitas, L.A., 2000. Different Leishmania species determine distinct profiles of immune and histopathological responses in CBA mice. Microbes Infect. 2, 1807-1815.

Lukacs, N.W., Kunkel, S.L., Strieter, R.M., Warmington, K., Chensue, S.W., 1993. The role of macrophage inflammatory protein 1 alpha in Schistosoma mansoni egg-induced granulomatous inflammation. J. Exp. Med. 177, $1551-1559$

Lowry, O.H., Osebrough, N.J., Farr, A.L., Randall, R.J., 1951. Protein measurement with the Folin phenol reagent. J. Biol. Chem. 193, 265275

Mendez, S., Reckling, S.K., Piccirillo, C.A., Sacks, D., Belkaid, Y., 2004. Role for $\mathrm{CD} 4(+) \mathrm{CD} 25(+)$ regulatory $\mathrm{T}$ cells in reactivation of persistent leishmaniasis and control of concomitant immunity. J. Exp. Med. 200, 201210.

Mukbel, R., Petersen, C.A., Jones, D.E., 2006. Soluble factors from Leishmania major-specific CD4+ T cells and B cells limit $L$. amazonensis amastigote survival within infected macrophages. Microbes Infect. 8, 2547-2555.

Mukbel, R.M., Patten Jr., C., Gibson, K.A.T.H., Ghosh, M.O.U.S., Petersen, C.H.R.I., Jones, D.E., 2007. Macrophage killing of Leishmania amazonensis amastigotes requires both nitric oxide and superoxide. Am. J. Trop. Med. Hyg. 76, 669-675.

Muzio, M., Bosisio, D., Polentarutti, N., D'amico, G., Stoppacciaro, A., Mancinelli, R., van't Veer, C., Penton-Rol, G., Ruco, L.P., Allavena, P., Mantovani, A., 2000. Differential expression and regulation of toll-like receptors (TLR) in human leukocytes: selective expression of TLR3 in dendritic Cells. J. Immunol. 164, 5998-6004.

Racoosin, E.L., Beverley, S.M., 1997. Leishmania major: promastigotes induce expression of a subset of chemokine genes in murine macrophages. Exp. Parasitol. 85, 283-295.

Ramer, A.E., Vanloubbeeck, Y.F., Jones, D.E., 2006. Antigen-responsive CD4+ $\mathrm{T}$ cells from $\mathrm{C} 3 \mathrm{H}$ mice chronically infected with Leishmania amazonensis are impaired in the transition to an effector phenotype. Infect. Immun. 74, $1547-1554$

Ramos-Santos, C., Hernandez-Montes, O., Sanchez-Tejeda, G., Monroy-Ostria, A., 2000. Visceral leishmaniosis caused by Leishmania (L.) mexicana in a Mexican patient with human immunodeficiency virus infection. Mem. Inst. Oswaldo Cruz 95, 733-738.

Ritter, U., Korner, H., 2002. Divergent expression of inflammatory dermal chemokines in cutaneous leishmaniasis. Parasite Immunol. 24, 295-301.

Ritter, U., Moll, H., 2000. Monocyte chemotactic protein-1 stimulates the killing of Leishmania major by human monocytes, acts synergistically with IFNgamma and is antagonized by IL-4. Eur. J. Immunol. 30, 3111-3120.

Ritter, U., Moll, H., Laskay, T., Brocker, E., Velazco, O., Becker, I., Gillitzer, R., 1996. Differential expression of chemokines in patients with localized and diffuse cutaneous American leishmaniasis. J. Infect. Dis. 173, 699-709.

Rocha, P.N., Almeida, R.P., Bacellar, O., de Jesus, A.R., Filho, D.C., Filho, A.C., Barral, A., Coffman, R.L., Carvalho, E.M., 1999. Down-regulation of Th1 type of response in early human American cutaneous leishmaniasis. J. Infect. Dis. 180, 1731-1734.

Santiago, H.C., Oliveira, C.F., Santiago, L., Ferraz, F.O., de Souza, D.G., De Freitas, L.A., Afonso, L.C., Teixeira, M.M., Gazzinelli, R.T., Vieira, L.Q., 2004. Involvement of the chemokine RANTES (CCL5) in resistance to experimental infection with Leishmania major. Infect. Immun. 72, 4918-4923.

Scharton, T.M., Scott, P., 1993. Natural killer cells are a source of interferon gamma that drives differentiation of CD4+ T cell subsets and induces early resistance to Leishmania major in mice. J. Exp. Med. 178, 567-577.

Soong, L., Xu, J.C., Grewal, I.S., Kima, P., Sun, J., Longley, B.J., Ruddle, N.H., Mahon-Pratt, D., Flavell, R.A., 1996. Disruption of CD40-CD40 ligand interactions results in an enhanced susceptibility to Leishmania amazonensis infection. Immunity 4, 263-273.

Spath, G.F., Beverley, S.M., 2001. A lipophosphoglycan-independent method for isolation of infective Leishmania metacyclic promastigotes by density gradient centrifugation. Exp. Parasitol. 99, 97-103.

Steigerwald, M., Moll, H., 2005. Leishmania major modulates chemokine and chemokine receptor expression by dendritic cells and affects their migratory capacity. Infect. Immun. 73, 2564-2567.

Stenger, S., Donhauser, N., Thuring, H., Rollinghoff, M., Bogdan, C., 1996. Reactivation of latent leishmaniasis by inhibition of inducible nitric oxide synthase. J. Exp. Med. 183, 1501-1514. 
Uzonna, J.E., Spath, G.F., Beverley, S.M., Scott, P., 2004. Vaccination with phosphoglycan-deficient Leishmania major protects highly susceptible mice from virulent challenge without inducing a strong Th1 response. J. Immunol. 172, 3793-3797.

Uzonna, J.E., Wei, G., Yurkowski, D., Bretscher, P., 2001. Immune elimination of Leishmania major in mice: implications for immune memory, vaccination, and reactivation disease. J. Immunol. 167, 69676974.

Vanloubbeeck, Y., Ackermann, M.R., Jones, D.E., 2005. Late cutaneous metastases in C3H SCID mice infected with Leishmania amazonensis. J. Parasitol. 91, 226-228.

Vanloubbeeck, Y., Jones, D.E., 2004. Protection of C3HeB/FeJ mice against Leishmania amazonensis challenge after previous Leishmania major infection. Am. J. Trop. Med. Hyg. 71, 407-411.
Vasquez, R.E., Soong, L., 2006. CXCL10/gamma interferon-inducible protein 10-mediated protection against Leishmania amazonensis infection in mice. Infect. Immun. 74, 6769-6777.

Veras, P., Brodskyn, C., Balestieri, F., Freitas, L., Ramos, A., Queiroz, A., Barral, A., Beverley, S., Barral-Netto, M., 1999. A dhfr-ts-Leishmania major knockout mutant cross-protects against Leishmania amazonensis. Mem. Inst. Oswaldo Cruz 94, 491-496.

Vieira, L.Q., Goldschmidt, M., Nashleanas, M., Pfeffer, K., Mak, T., Scott, P., 1996. Mice lacking the TNF receptor p55 fail to resolve lesions caused by infection with Leishmania major, but control parasite replication. J. Immunol. 157, 827-835.

Zaph, C., Scott, P., 2003. Interleukin-12 regulates chemokine gene expression during the early immune response to Leishmania major. Infect. Immun. 71, $1587-1589$. 